\title{
The investigation of frequency response analysis for power transformers winding condition
}

\author{
Artyom Nazarov ${ }^{1}$, Vitaliy Savelev ${ }^{2 *}$ and Dennis Frogh \\ ${ }^{1}$ AO GK Sistemy i tekhnologii, Department of science, 600014 Vladimir, Lakina st, 8, Russian Federation \\ ${ }^{2}$ AO GK Sistemy i tekhnologii, Department of science, 600014 Vladimir, Lakina st, 8, Russian Federation
}

\begin{abstract}
In modern electrical transmission and distribution systems, power transformers are critical components within the network. In the event that a failure occurs in service, the impact can be far reaching. The majority of mechanical deformation within power transformers is due to short circuit faults. The ageing transformer population increases the likelihood of failure so a reliable diagnostic tools required to determine the remaining life of these assets. Although, frequency response analysis (FRA) has been recently recognized as the most reliable detection tool for mechanical deformation in transformers, in the event of minor fault, the current FRA interpretation approach may not able to detect any variations between healthy and faulty FRA signatures. This paper focuses on FRA tests for power transformer and interpretation of obtained FRA signatures.
\end{abstract}

One of the most important problems of transformer maintenance is the monitoring system and technical diagnosis development. More than $40 \%$ of transformers have exceeded their design life $(25 \mathrm{y}$, established by standard papers [1]). Nowadays, there are several diagnostic techniques for power transformers, for example, vibration analysis, ultrasonic contact fault detection, dielectric loss angle test and partial discharge [2]. The diagnosis of power transformer can be carried out offline, online and partly. Parameters used for online transformer tests are temperature, pressure, leakage currents, vibration amplitude, noise level, velocity vibration and acceleration vibration. They must have properties, such sensitivity, accuracy of measurement, stability, depth of investigation and simplicity of diagnosis. The transformer defects occur due to unsuitable means of transporting short circuit currents, earthquakes, oil ignition in tank etc [3]. Due to CIGRE working group A 2.26 the most common cause of power transformers fault is inter-disk faults [4].

One of the most effective techniques of condition monitoring for power transformers are Sweep Frequency Response Analysis (SFRA) and Impulse Frequency Response Analysis (IFRA) [5]. Lots of investigations are held to improve this technique at the moment, but from 1978 there is no general opinion how to make a conclusion about technical condition [6].The main advantage of this technique is its high sensitivity: even minor local changes of winding elements(turns, disks) result in dramatic changes on diagnosis signature [7]. Different types of deformations lead to changes in FRA signature in different range. Conventional techniques of condition monitoring are not so sensitive. That's why FRA is the best technique for inter-disk fault detection.

Frequency Response Analysis has two directions of use: sweep and impulse [3].
IFRA is provided by low voltage impulse given on winding (The impulse form can be rectangular or conventional or exponential). Current or voltage on bushing terminals or frequency current transformers of other windings is measured. The transition process in windings is recorded with the help of analog-digital converters. After that the response is transformed to frequency area using Fourier algorithm. Finally, transfer function as a ratio of injected and measured signal is founded.

SFRA is used in frequency area directly. In this case the sine $10 \mathrm{~V}$ signal from sweep generator is injected on the bushing terminal. It's changes from several $\mathrm{Hz}$ to several MHz. The response is measured from other terminals as a function of the variable frequency [3]. Each way has its advantages and disadvantages. For example, SFRA is more sensitive on low frequencies and quite simple maintenance as much as in interpretation results [8]. However the process takes long time.

A foreign power transformer was selected as an object of study. Its characteristics are given in table 1 . This transformer was chosen because of its initial data, which were used for modelling.

Table 1. The power transformer parameters

\begin{tabular}{|c|c|c|}
\hline № & Classification & Value \\
\hline 1 & Rated power & $40 \mathrm{MVA}$ \\
\hline 2 & Impedance & $13,8 \%$ \\
\hline 3 & Primary voltage & $66 \mathrm{kV}$ \\
\hline 4 & Secondary voltage & $11 \mathrm{kV}$ \\
\hline 5 & Height of HV winding & $1074 \mathrm{~mm}$ \\
\hline 6 & Height of LV winding & $1136 \mathrm{~mm}$ \\
\hline 7 & Core cross-section diameter & $560 \mathrm{~mm}$ \\
\hline 8 & Insulated core cross-section diameter & $579 \mathrm{~mm}$ \\
\hline 9 & Inner diameter of HV winding & $825 \mathrm{~mm}$ \\
\hline 10 & Inner diameter of LV winding & $612 \mathrm{~mm}$ \\
\hline 11 & Primary turns & 1200 \\
\hline 12 & Secondary turns & 200 \\
\hline
\end{tabular}


The parameters of the frequency characteristics with the parameters of the winding could be correlated because the power transformer winding is a multi-frequency oscillatory circuit [9]. It consists of series resistance, series inductance and series capacitances.

A transformer winding equivalent circuit was compiled in the Multisim software package to carry out the experiments (fig.1).Transformer parameters are:

- series inductance and series resistance of HV and LV windings $\left(\mathrm{L}_{\mathrm{s}}, \mathrm{R}_{\mathrm{s}}\right)$;

- shunt capacitance between HV and LV windings $\left(\mathrm{C}_{\mathrm{sh}}\right)$;

- series capacitances between $\mathrm{HV} / \mathrm{LV}$ windings and the earthed tank / core $\left(\mathrm{C}_{\mathrm{o}}\right)$;

- series capacitances between the HV and LV windings $\left(\mathrm{C}_{\mathrm{HL}}\right)$.

Table 2. Parameters of the equivalent circuit [10]

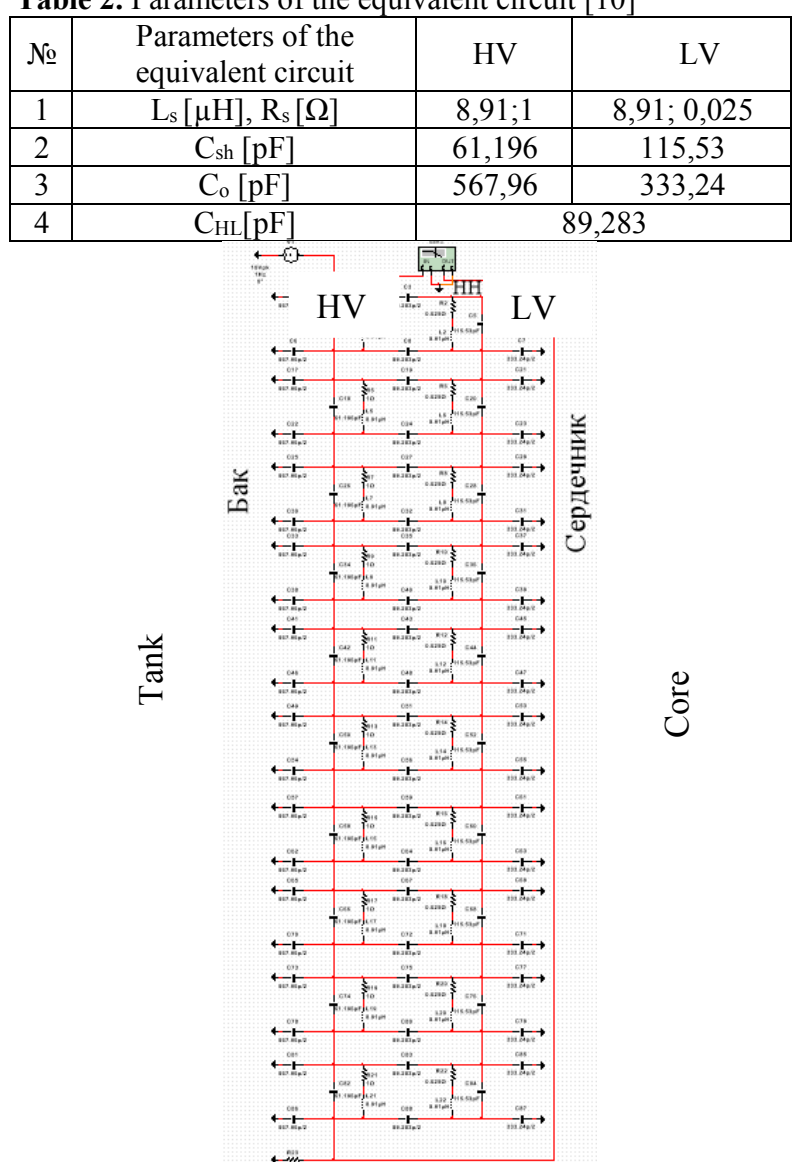

Fig. 1. The equivalent circuit of HV and LV winding

The equivalent circuit of the first $\mathrm{HV}$ winding disk is shown in Fig. 2.

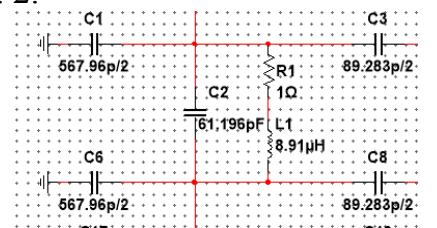

Fig. 2. The equivalent circuit of the first HV winding disk
$\mathrm{C}_{1}, \mathrm{C}_{6}\left(\mathrm{C}_{\mathrm{o}}\right)$ - capacitance between first $\mathrm{HV}$ winding disk and the earthed tank

$\mathrm{C}_{2}\left(\mathrm{C}_{\mathrm{sh}}\right)$ - capacitance between first and second $\mathrm{HV}$ winding disk.

$\mathrm{C}_{3}, \mathrm{C}_{8}\left(\mathrm{C}_{\mathrm{HL}}\right)$ - capacitance between first $\mathrm{HV}$ winding disk and $\mathrm{LV}$ winding.

$\mathrm{L}_{1}\left(\mathrm{~L}_{\mathrm{s}}\right)$ - inductance of the first HV winding disk.

$\mathrm{R}_{1}\left(\mathrm{R}_{\mathrm{s}}\right)$ - resistance of the first $\mathrm{HV}$ winding disk.

To conduct tests, the elements implemented in Multisim in the form of blocks were used. They are:

- The generator of sine signal, which allows to change the amplitude, frequency and duration of the signal. The amplitude is $10 \mathrm{~V}$.

- BodePlotter, used to get FRA signature.

- Load resistance, which consists of the cable resistance and measuring instrument resistance, etc. The view of the BodePlotter block is shown in Fig.

3.

Fig. 3. BodePlotter block

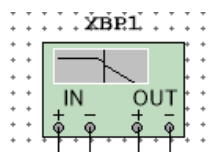

The view of the generator of sine signal block is shown in Fig. 4.

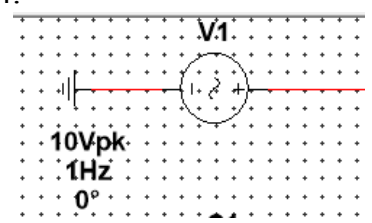

Fig. 4. The generator of sine signal block

The view of load resistance block is shown in Fig. 5

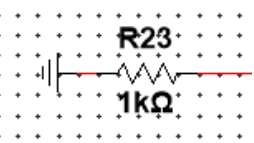

Fig. 5. The load resistance block

During FRA test the transfer function - frequency response was found. This function is the ratio of injected signal on the top of the winding to the measured signal from the winding end. It's a plot, defined by frequency

Each of $10 \mathrm{HV}$ winding disks was short-circuited in this test.

Under the test capacitance $\mathrm{C}_{\mathrm{sh}}\left(\mathrm{C}_{2}\right)$ was enlarged in 100 times. It was made to ensure accurate results. At one plot damaged transformer FRA signature and healthy transformer FRA signature were placed. (fig. 6, fig.7 and fig. 8).

Fig. 6 shows: healthy transformer FRA signature, the first, the second and the third short-circuited winding disk FRA signature. Fig. 7 shows: healthy transformer FRA signature, the fourth, the fith, the sixth and the seventh short-circuited winding disk FRA signature. Fig. 8 shows: healthy transformer FRA signature, the eighth, the nineth and the tenth short-circuited winding disk FRA signature 


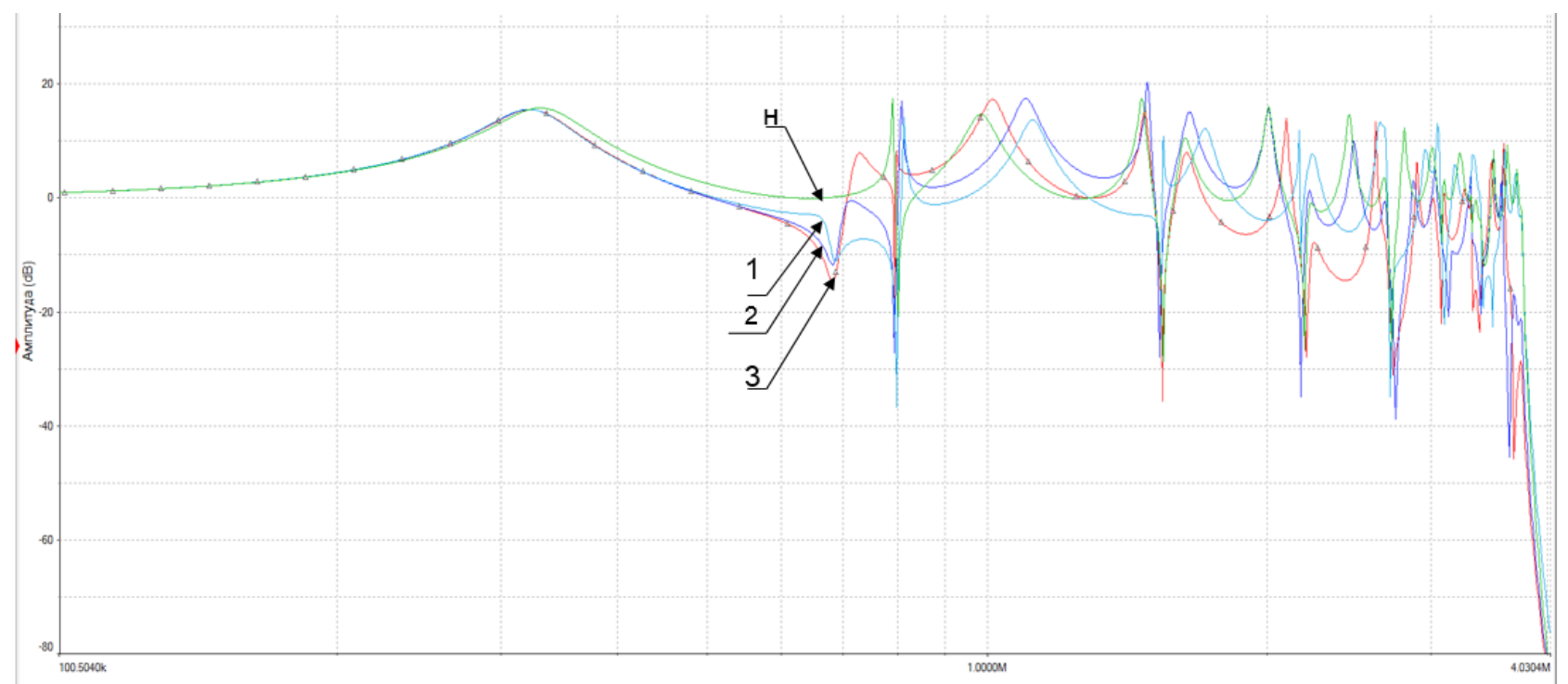

Fig. 6. The plot of transfer function $(\mathrm{dB})$ as a function of frequency. Disk windings short-circuited in series. $\mathrm{H}-\mathrm{healthy}$ disk windings condition, 1 - first disk winding short-circuited, 2 - second disk winding short-circuited, 3 - third disk winding shortcircuited.

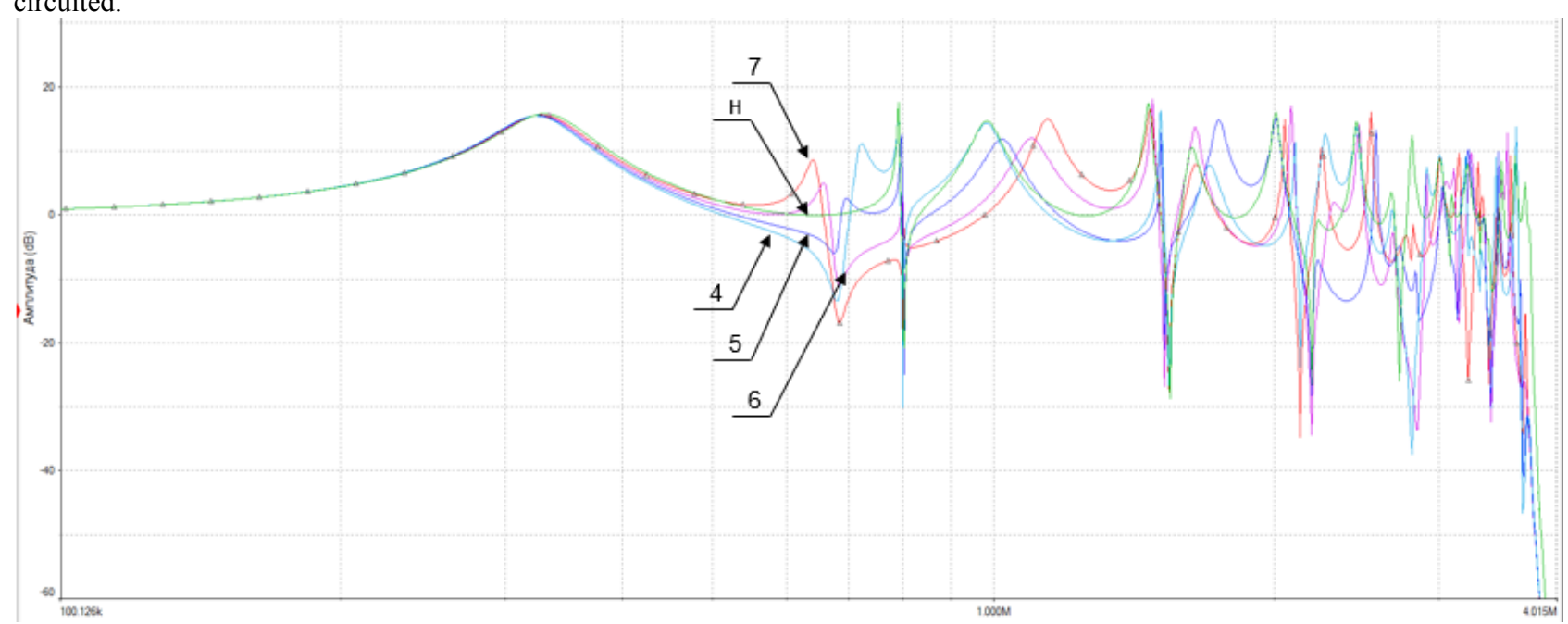

Fig. 7. The plot of transfer function $(\mathrm{dB})$ as a function of frequency. Disk windings short-circuited in series. $\mathrm{H}$ - healthy disk windings condition, 4 - fourth disk winding short-circuited, 5 - fifth disk winding short-circuited, 6 - sixth disk winding shortcircuited, 7 - seventh disk winding short-circuited.

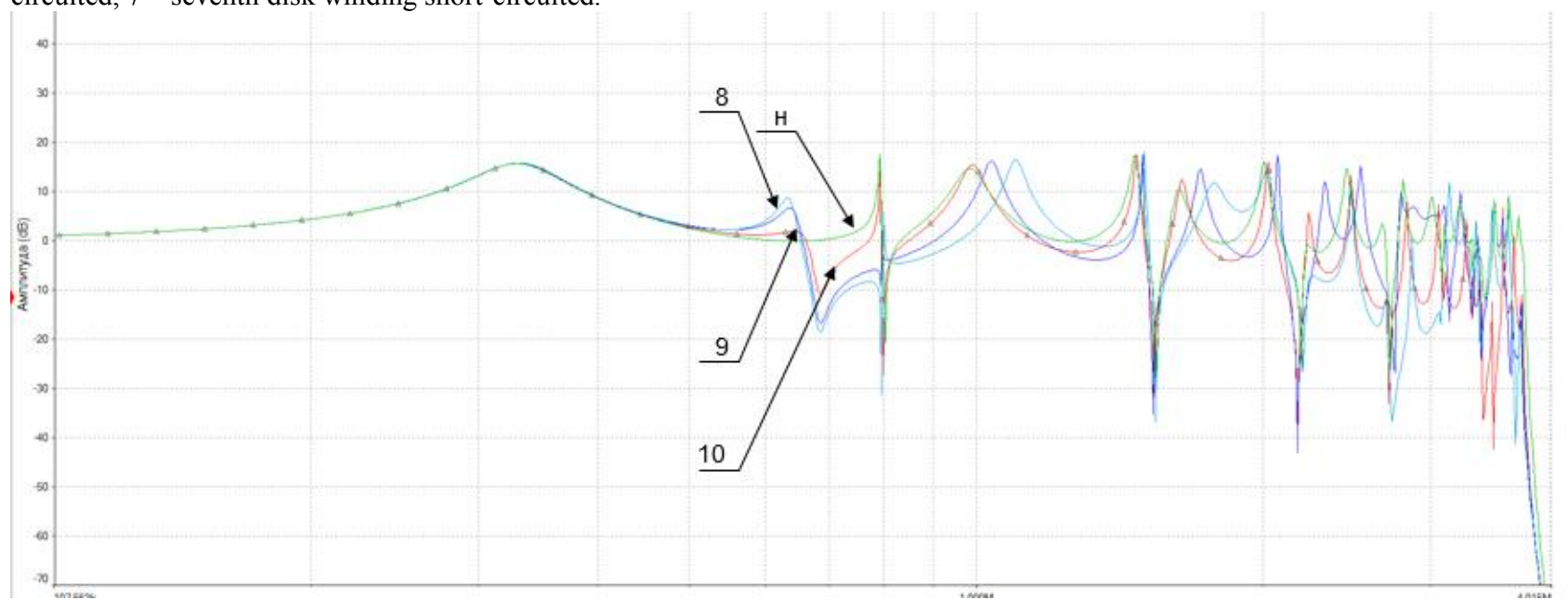

Fig. 8. The plot of transfer function $(\mathrm{dB})$ as a function of frequency. Disk windings short-circuited in series. $\mathrm{H}-\mathrm{healthy}$ disk windings condition, 8 - eighth disk winding short-circuited, 9 - nineth disk winding short-circuited, 10 - tenth disk winding shortcircuite 
To compare damaged and healthy FRA signatures it is noticed:

- before $2 \mathrm{MHz}$ changes in curves are noticeable;

The first resonance frequency on heathy winding is about $\sim 320$ кГц, and the first antiresonanse is $\sim 800 \kappa \Gamma ц$; When frequency changes from $1,5 \mathrm{MHz}$ to $4 \mathrm{MHz}$ there are lots of resonanses and antiresonanses. When different disk winding short-circuited the next thing should be marked:

- fig.6 shows the growth of resonance amplitude at displacement from 1 disk to 3 disk on $\sim 680$ $\mathrm{kHz}$;

- fig. 7 shows the growth both resonance and antiresonanse displacement amplitude at the middle of the winding( from 4 disk to 7 disk);

- The decrease of resonance amplitude is observed at the end of the winding (from 8 to 10 disk);

- The first resonance frequency varies from 500 $\mathrm{kHz}$ to $600 \mathrm{kHz}$, depending of the fault place.

The changes above were observed at $\sim 680 \mathrm{kHz}$.

The amplitude varies from 18 to $-43 \mathrm{~dB}$. After that, the signal is decreasing.

\section{Conclusion}

1. FRA could be used as a technique of power transformer winding diagnosis .

2. To explain FRA results the equivalent circuit was made in Multisim. It helps to make an experiments on disk windings

3. To make an experiment the series capacitances, series inductance and series resistance has to be known

4. Using FRA for diagnosis, the algorithm of fault windings determination should be developed.

5. Winding deformation comes to changes in inductance and capacitance, so FRA signature is changing too (number of resonanses, amplitude, location on the curve).

6. The most informative part of FRA signature located from $500 \mathrm{kHz}$ to $600 \mathrm{kHz}$. The reason is that till 1 $\mathrm{kHz}$ there are a lot of electromagnetic noises in power grid and over $2 \mathrm{MHz}$ the response is too much sensitive to all electromagnetic changes.

7. The change of series resistance connected with increase or decrease amplitude of FRA signature.

8. The first antiresonanse frequency moved to the right at the change of fault location from the top to the middle. The amplitude increases.

\section{References}

1. M. Y. Lvov Damage analysis of power transformers with voltage of $110 \mathrm{kV}$ and higher Elektrichestvo,2, (2010).

2. O. A. Kuzmin Modern diagnostic methods for power transformers URL:https://energoboard.ru/post/411/

3. Drobyshevsky A.A. Electrodynamic stability of power transformers - Novosti elektrotekhniki, №5(65), (2010).

4. CIGRE Working Group A2.26, "Mechanicalcondition assessment of transformer windings using frequency response analysis (FRA)" 2007.

5. Rahimpour, Hossein \& Mitchell, S.D. \&Tusek, Joe. (2016). The application of sweep frequency response analysis for the online monitoring of power transformers. 1-6. 10.1109/AUPEC.2016.7749347.

6. E. P. Dick and C. C. Erven, "Transformer diagnostic testing by fre-quency response analysis," IEEE Trans. Power App. Syst., vol. PAS-97, no. 6, pp. 2144-2153, Nov. 1978.

7. Steven D. Mitchell and James S. Welsh, "Modelling Power Trans-formers to Support the Interpretation of Frequency-Response Analysis", IEEE transactions on power delivery, vol. 26 , no. 4 , October 2011

8. Belinda J Small and A. Abu-Siada «A New Method for Analysing Transformer Condition Using Frequency Response Analysis» 1-5. 10.1109/PES.2011.6039470.

9. R.G. Ildarkhanov «Diagnosis of defects in transformer windings using low voltage pulses» Energetika Tatarstana, №1 (2009).

10. O. Aljohani, A. Abu-siada, and S. Islam «Impact of Insulating Oil Degradation on the Power Transformer Frequency Response Analysis» IEEE 11th International Conference on the Properties and Applications of Dielectric Materials (ICPADM), 2015 